\title{
Physiological Features during the Copper Switch in Methylococcus Capsulatus (Bath)
}

\author{
Ashraf Y.Z. Khalifa
}

\begin{abstract}
Copper-to-biomass ratio is an important factor that controls the biosynthesis and catalytic activity of the two forms (particulate or soluble) of methane monooxygenase enzyme in Methylococcus capsulatus (Bath). Under growth conditions of high copper-to-biomass ratio, the particulate enzyme is expressed while the soluble enzyme is up-regulated when this ratio is low. It is of interest to explore physiological features of cells in response to copper addition. To this end, $M$. capsulatus was grown on Nitrate Mineral Salts medium in a bioreactor and $30 \mu \mathrm{M}$ copper was added at a dilution rate of 3.3

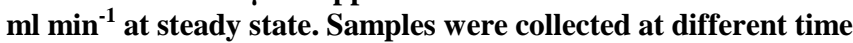
points and assayed for soluble methane monooxygenase (sMMO) expression using the naphthalene assay, SDS-PAGE of total cell protein and copper measurements. The results showed that the activity of sMMO was gradually decreased upon gradual copper addition until it became fully inactive after 4 hours of adding copper. Furthermore, the intracellular, extracellular and copper associated with biomass increased by adding copper over the time tested. Eleven bands from the SDS-PAGE gel of sMMO-expressing cells and pMMO-expressing cells, were analyzed by mass spectrometry. The results highlighted that 128 proteins were identified from $\mathbf{7 9 2}$ polypeptides detected from the eleven bands analysed. Typically, 506 polypeptides from sMMO-expressing cells (corresponding to 87 proteins) and 236 from pMMO-expressing cells (corresponding to 41) were identified. Collectively, the results confirmed that copper negatively regulates sMMO and induces pMMO in $M$. capsulatus.
\end{abstract}

Index Terms-Copper Switch, Methylococcus capsulatus, Naphthalene assay.

\section{INTRODUCTION}

Methanotrophs is a ubiquitous group of bacteria capable of growth on methane as their sole energy and carbon source [1], [2]. Methanotrophic bacteria is a subdivision of the methylotrophs, which are a diverse group of organisms able to utilize different compounds containing a single-carbon atom e.g., methanol, methylated amines, halomethanes [3], [4].

Methane monooxygenase (MMO) is the pivotal enzyme that methanotrophs contain since it catalyses the oxidation methane to methanol [1], [5]. There are two types of MMO: a particulate methane monooxygenase (pMMO) and a cytoplasmic or soluble methane monooxygenase enzyme (sMMO). Either pMMO or sMMO exist in methanotrophs although some genera contain both. The majority of methanotrophs possesses a particulate methane monooxygenase enzyme whereas a few species contain only

Manuscript received October 19, 2012; revised December 2, 2012.

Ashraf Y. Z. Khalifa is with the Botany Department, University of Beni-Suef, Beni-Suef, Egypt (e- mail: ashraf_zaky2002@yahoo.com ). soluble methane monooxygenase enzyme e.g., Methylocella silvestris [6], [7] and Methyloferula stellata [8].

Methylococcus capsulatus Bath is an obligate methanotroph bacterium, which possess pMMO and sMMO and the expression and activity of the two types of MMO is significantly affected by the bioavailability of copper [9], [10]. pMMO is expressed at high copper to-biomass ratios whereas sMMO is expressed at low copper-to-biomass ratios growth conditions [8]. Furthermore, copper enhances the synthesis of an extensive network of intracytoplasmic membranes [11] and is the active center metal of pMMO [12].

The term 'copper switch' is given for methanotrophs that contain sMMO and pMMO and describes the expression shift to sMMO from pMMO at low-copper conditions. When copper -to-biomass ratio equals or exceeds $1 \mu \mathrm{mol} \mathrm{g}^{-1}$ dry weight of cells, the switch from sMMO to pMMO transcription occurs [7], [13]. Although M. capsulatus has been studied extensively over the past 40 years, the exact role of copper in regulation of MMO is still unclear. Therefore, the basis of this study was to investigate the physiological features of $M$. capsulatus during the copper switch. To fulfill this goal, $M$. capsulatus was grown on NMS medium with no-added copper in a fermentor. When cells expressed sMMO as indicated by a positive naphthalene assay, the fermentor was switched to continuous mode; fresh NMS medium with 30 $\mu \mathrm{M}$ copper was added. Samples were collected -at continuous steady state- at different time points and assayed for soluble methane monooxygenase (sMMO) expression using the naphthalene assay, SDS-PAGE of total cell protein and copper measurements. Furthermore, eleven bands from the SDS-PAGE gel of sMMO-expressing cells and pMMO-expressing cells were analyzed by mass spectrometry.

\section{MATERIALS AND METHODS}

\section{A. Growth of M. capsulatus in Fermentor}

M. capsulatus was grown on NMS medium with no-added copper in $5 \mathrm{~L}$ fermentor (Inceltech LH Series 210). The physical parameters of the fermentor were adjusted as follows: methane flow $\left(140 \mathrm{ml} \mathrm{min}^{-1}\right)$, air flow $\left(1 \mathrm{~L} \mathrm{~min}^{-1}\right)$, the dissolved oxygen level in the fermentor vessel (above $5 \%$ ) and $\mathrm{pH}(6.8-7.0)$. About $400 \mathrm{ml}$ of late exponential phase $M$. capsulatus flask-grown culture was used as inoculum. Samples were taken regularly and $\mathrm{OD}_{540}$ was measured as a growth check and samples of the culture were tested for sMMO expression using the naphthalene oxidation assay. When cells expressed sMMO $\left(\mathrm{OD}_{540} \sim 5\right)$, as indicated by a positive naphthalene assay, the fermentor was switched to continuous 
mode, sterile fresh NMS medium with $30 \mu \mathrm{M}$ copper was added via a calibrated peristaltic pump at a dilution rate of $3.3 \mathrm{ml} \mathrm{min}^{-1}$ and maintained at steady state. The outflow was collected in a sterile $25 \mathrm{~L}$ carboy. Just before adding NMS medium, a sample $(20 \mathrm{ml})$ was taken and considered as $\mathrm{t}=0 \mathrm{~h}$. At this stage cells were expressing sMMO i.e. before copper switch. Then different samples were taken at different time points; 0.12, 0.25, 0.5, 1, 2, 3, 4, 5, 6, 7, 8, 19 and 40h. Each sample was divided into different tubes for subsequent measurements; naphthalene assay, SDS-PAGE of total cell protein and copper measurements. The different stages of the of the experimental design flow are outlined in the schematic representation in Fig. 1.

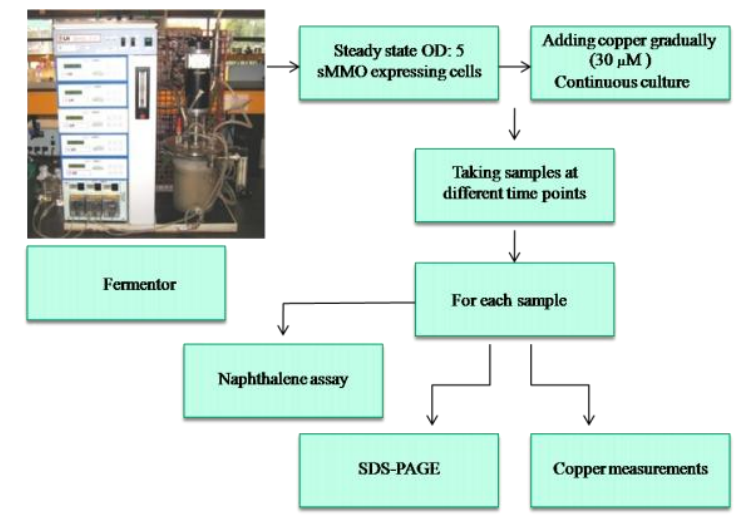

Fig. 1. Schematic representation of the experimental design flow.

\section{B. Naphthalene Assay to Check sMMO Activity}

To check for sMMO expression, all M. capsulatus samples were tested using the naphthalene oxidation assay according to the method mentioned previously [2]. Cells were incubated with few crystals of naphthalene for $30 \mathrm{~min}$ at $45^{\circ} \mathrm{C}$. A positive result was shown by a purple colour developing upon addition of a few drops of a freshly prepared solution of the zinc complex tetrazotized $o$-dianisidine $\left(10 \mathrm{mg} \mathrm{ml}^{-1}\right)$. This result was taken as evidence for sMMO expression.

\section{Cell-free Extract Preparation}

Typically, $5 \mathrm{ml}$ of $M$. capsulatus cultures of $\sim \mathrm{OD}_{540} 5$ were harvested by centrifugation at $10,000 \times \mathrm{g}$, for $20 \mathrm{~min}$ at $4{ }^{\circ} \mathrm{C}$. Pellets were washed in fresh NMS medium and resuspended in $3 \mathrm{ml}$ phosphate buffer ( $\mathrm{pH}$ 6.8) containing 1 $\mathrm{mM}$ benzamidine to inactivate proteases. To break cells, cell suspensions were passed through a pre-cooled French pressure cell (American Instrument Company, Silver Spring, $\mathrm{MD})$ at $110 \mathrm{MPa}$. Centrifugation $\left(10,000 \times \mathrm{g}, 20 \mathrm{~min}, 4{ }^{\circ} \mathrm{C}\right)$ was carried out to remove cell debris. The supernatant was carefully transferred to new tubes and considered as cell-free extract, which was then used for SDS-PAGE.

\section{Estimation of Protein Concentration}

Bio-Rad Protein Assay (Bio-Rad Laboratories Inc., Hercules, CA, USA) was used to estimate protein concentrations following the manufacturer's instructions. A standard curve was made using different concentrations of bovine serum albumin (BSA) $(0-100 \mu \mathrm{g})$.

\section{E. Sodium Dodecyl Sulfate Polyacrylamide Gel Electrophoresis Analysis}

Sodium dodecyl sulfate polyacrylamide gel electrophoresis
(SDS-PAGE) analysis was carried out using an X-cell II Mini-Cell apparatus (Novex) to separate polypeptides. Sample loading buffer (1/4 volume of the sample) was added to cell-free extracts and the mixture was boiled for $10 \mathrm{~min}$ then centrifuged $\left(10,000 \times \mathrm{g}, 15 \mathrm{~min}, 4{ }^{\circ} \mathrm{C}\right)$. Typically $40 \mu \mathrm{g}$ protein was loaded in each lane. Dalton Mark VII-L ${ }^{\text {TM }}$ protein marker (Sigma) or PageRuler Plus prestained protein ladder (Fermentas) was used to determine the molecular masses of the protein bands. Running buffer ( $1 \mathrm{x}$ ) was added to the tank of $\mathrm{X}$-cell II Mini-Cell apparatus and electrophoresis was performed. The voltage applied during separation of polypeptides through the stacking gel was $90 \mathrm{~V}$ while $160 \mathrm{~V}$ was applied during separation through the resolving gel. After electrophoresis, gels were carefully placed in Coomassie brilliant blue staining solution ( $(0.1 \%$ (w/v) Coomassie brilliant blue R-250 dissolved in $40 \%$ methanol, $10 \%$ acetic acid and $50 \%$ water) and gently shaken overnight. Gels were then destained using destaining solution (40\% (v/v) methanol and $10 \%(\mathrm{v} / \mathrm{v})$ acetic acid).

\section{F. Analysis of Polypeptides Using MS/MS}

In order to confirm the identity of polypeptides of both sMMO and pMMO, prominent eleven bands (Fig. 4) in lanes 2 (at 0h, sMMO-expressing cells) and 9 (at 40h, pMMO-expressing cells) were cut out from the SDS-PAGE gel. Each band was divided into $4-6$ small cubes, transferred in known order into 96-well microtiter plate and $200 \mu \mathrm{l}$ de-ionized water was added. Samples were digested with trypsin and analyzed by Nano liquid chromatoghraphy electrospray ionization tandem mass spectrometry (nanoLC-ESI-MS/MS) using the NanoAcquity/Q-ToF Ultima Global instrumentation (Waters). The data were used to interrogate the $M$. capsulatus protein database using the Protein Lynx Global Server v2.4 and protein identities were assigned

\section{G. Copper Measurements}

To ensure no copper contamination, all glassware was acid-washed then rinsed in deionised water several times. The cultures were centrifuged at $12,000 \times \mathrm{g}$ for $10 \mathrm{~min}$ and the supernatant stored at $-80{ }^{\circ} \mathrm{C}$. Cell pellets were resuspended in $0.1 \% \mathrm{NaCl}$ and centrifuged. This supernatant was considered to represent biomass-associated copper. Cell pellets were dried then dissolved in $5 \mathrm{ml}$ of nitric acid (70\%). The copper in this fraction was considered as intracellular copper. Samples were diluted to $3 \mathrm{ml}$ in $0.1 \mathrm{M}$ trace metal grade nitric acid obtained from Sigma. All samples were measured using an atomic absorption spectrophotometer.

\section{RESULTS}

\section{A. Naphthalene Assay to Check sMMO Activity}

The Naphthalene assay results showed a gradual decrease in the intensity of the purple colour (positive naphthalene test) with gradual addition of copper over the time course tested (Fig. 2). However, the first eight samples exhibited positive results for naphthalene oxidation, while samples taken after 4h showed no purple colour appearance when zinc reagent 
was added, which indicated that sMMO had become inactive. As expected, the two negative controls showed no change in colour (yellow); one tube had culture with no naphthalene added and the other was no-cells control. The positive control in which Methylocella silvestris was added, showed a positive result (a purple colour) (Fig. 2). Methylocella silvestris possesses only sMMO and does not contain pMMO.

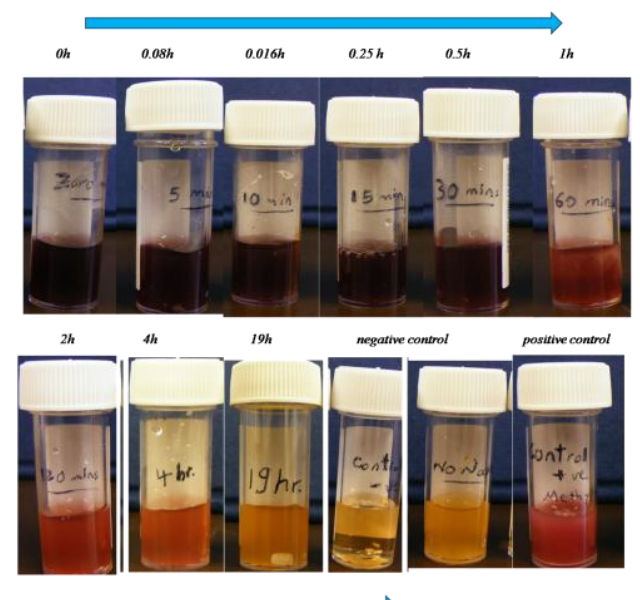

Fig. 1. Results of naphthalene oxidation assay at representative time points, the arrows indicate the gradual decrease in the intensity of the purple from deep at $0 \mathrm{~h}$ to pale purple at $4 \mathrm{~h}$ then yellow colour after $4 \mathrm{~h}$. Purple colour: positive result (sMMO expressed), yellow colour: negative result (pMMO expressed).

These results indicated that the copper switch from sMMO to pMMO is likely to occur between $2-5 \mathrm{~h}$ based on the results of naphthalene test (Fig. 2). In addition, these observations confirm that copper negatively regulates sMMO activity in $M$. capsulatus.

\section{B. SDS-PAGE}

To identify the different patterns of polypeptides of both sMMO and pMMO SDS-PAGE analysis was carried out.

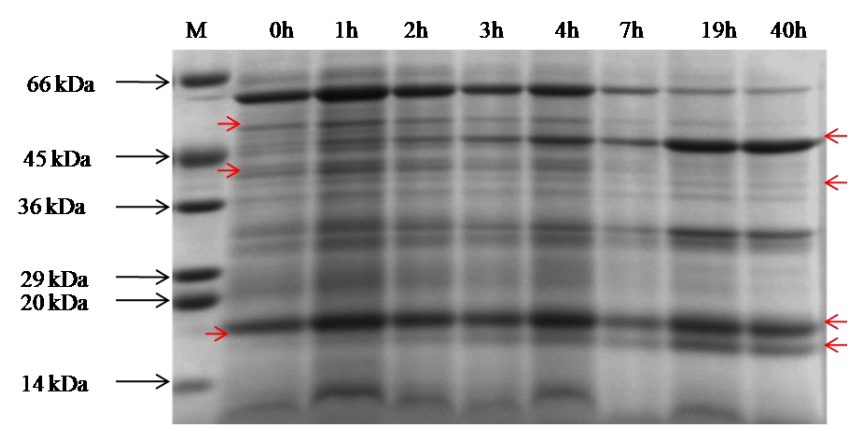

Fig. 2. A Coomassie-stained 12.5\% SDS-PAGE gel of cell-free extracts from $M$. capsulatus. The red arrows on the left point to the three subunits of the hydroxylase component; $\alpha^{-}, \beta-$ and $\gamma$-subunits of the sMMO and the right the three subunits of the pMMO. M, a Dalton VII molecular marker was used on the left of the samples and the sizes are indicated on the side. Time points after initial addition of copper-containing NMS medium were indicated in hours at the top of each lane.

As can be shown in (Fig. 3), the $\alpha$ - and $\beta$-subunits of the hydroxylase of the sMMO were detected and their intensities gradually decreased with time. These bands correspond to the MmoX (61 kDa), MmoY (45 kDa) and MmoZ (20 kDa) of sMMO. On the other hand, the intensities of the bands corresponding to $\alpha-, \beta-$ and $\gamma$-subunits, which correspond to PmoB (47 kDa), PmoA (24 kDa) and PmoC (22 kDa), of the hydroxylase of pMMO, increased with time in a gradual manner. The top band at approximately $63 \mathrm{kDa}$ visibly detected in lanes from all samples was methanol dehydrogenase (MDH). MDH became less abundant with addition of copper over the time course. The results are in general agreement with those obtained with the naphthalene oxidation assay. Furthermore, the results revealed that copper-switch from sMMO to $\mathrm{pMMO}$ seemed to take place at about $4 \mathrm{~h}$.

\section{Analysis of Polypeptides Using MS/MS}

The results of LC/ECI-MS/MS analysis results showed that 128 proteins were identified from 792 polypeptides detected from the eleven bands analyzed. Typically, 506 polypeptides from sMMO-expressing cells (corresponding to 87 proteins) (Table 1) and 236 from pMMO-expressing cells (corresponding to 41) (Table 2) were identified. The most five abundant proteins in each band were presented in Tables 1 and 2. It was apparent that the major subunits of the hydroxylase of the sMMO were identified in the no-added copper growth conditions, while those of the pMMO were detected after adding of copper by 40 hours (Tables 2). Under no-added copper growth conditions, MmoX, MmoY in addition to the $\mathrm{MmoG}$ were identified, while PmoB, PmoA and PmoC were detected in the added copper growth conditions.

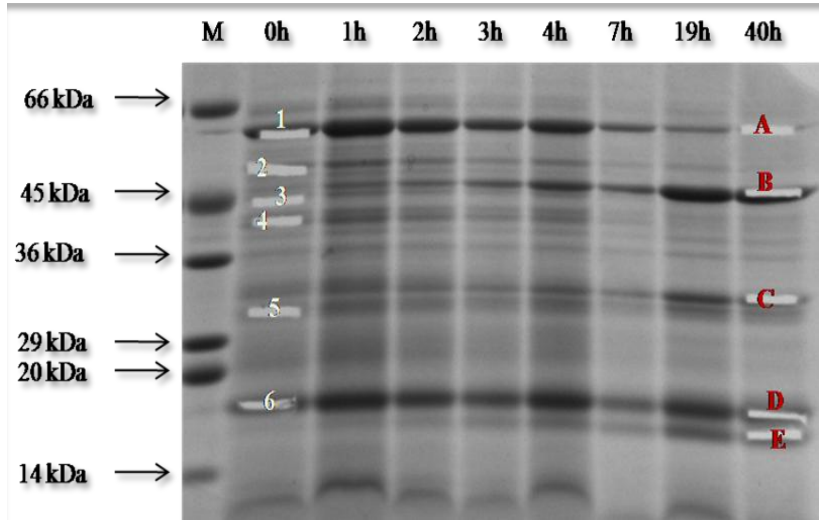

Fig. 3. A Coomassie stained $12.5 \%$ SDS-PAGE gel shown in Fig. 3 indicating the bands, which were selected for mass-spectrometric analysis. The numbers and letters identify bands, which were analyzed from cell-free extracts of samples collected at $0 \mathrm{~h}$ and $40 \mathrm{~h}$ respectively. Band-identifying numbers and letters refer to Table 7.1 and 7.2 respectively.

Methanol dehydrogenase (MDH) was also detected in all bands of both lanes 2 and 9 and represented $20 \%$ of the total polypeptide identified. However, the abundance of MDH was much higher in no-added copper (lane 2 (137 polypeptides)) than that in high-copper growth conditions (lane 9 (43 polypeptides)). Inorganic $\mathrm{H}^{+}$translocating pyrophosphatase and surface associated protein MopE were also detected in a relatively high abundance, 13 and 20 polypeptides respectively (Tables 1 and 2 ). These data are in general consistent with those obtained from the transcriptome analysis. These results indicated sMMO is expressed under low-copper-to-biomass ratio while pMMO is expressed under high-copper-to-biomass ratio growth conditions.

\section{Copper Measurements}

Intracellular, extracellular and copper associated with biomass was measured and as expected the copper concentrations is increased with time (Fig. 5). 


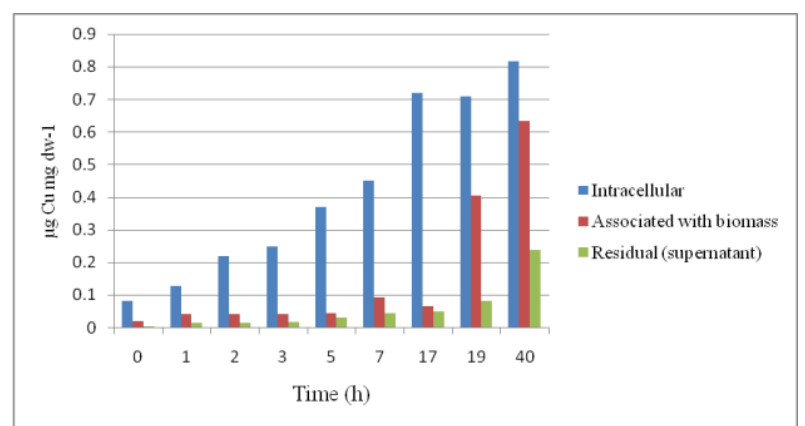

Fig. 5. Copper distribution in samples of M. capsulatus cultures at different time points

The intracellular copper concentration of $M$. capsulatus increased with the gradual addition of copper to the medium over the time course applied. At $0 \mathrm{~h}$ (no added copper), the cells accumulated $0.083 \mu \mathrm{g} \mathrm{Cu}\left(\mathrm{mg} \mathrm{dw}^{-1}\right.$, (note that the background copper resulted from copper contamination in the medium is about $0.8 \mu \mathrm{M}$. The accumulation rate of the intracellular copper of M. capsulatus is presented in Fig. 6. The cells seemed to take up copper more rapidly during the first seven hours than afterwards (Fig. 6). At 17h and 19h the cells exhibited comparable rate of accumulation of copper. The slowest rate of copper accumulation and the highest copper content recorded was at $40 \mathrm{~h}$. These data indicated that the copper-starved cells of $M$. capsulatus accumulated more copper intracellularly at a high rate during the early hours of addition of copper to the growth medium. Then, cells decreased the rate at which copper is accumulated. This copper could be used to produce active pMMO and copper-containing cytochrome oxidases as well as copper-containing enzymes.

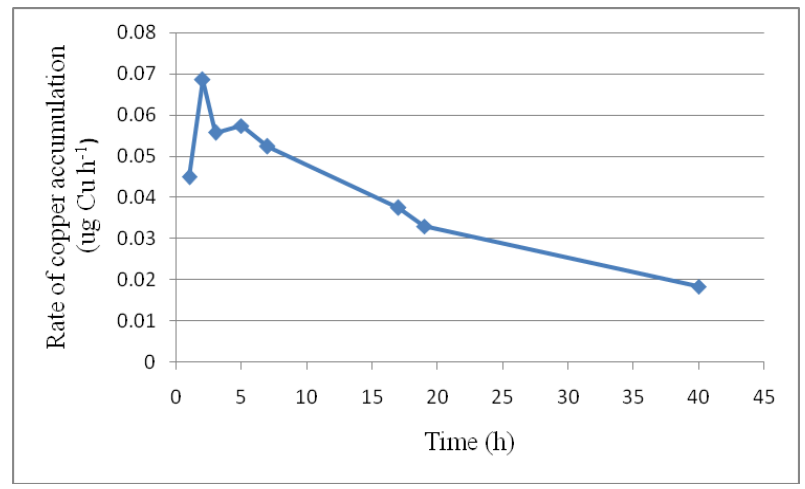

Fig. 6. Rate of copper accumulation inside $M$. capsulatus. The rate is expressed as ug $\mathrm{Cu} \mathrm{h}^{-1}$

The copper associated with the cell biomass appeared to be low over the first seventeen hours with an average concentration about $0.04 \mu \mathrm{g} \mathrm{Cu}\left(\mathrm{mg} \mathrm{dw}^{-1}\right.$. The amount of copper retained outside the cells increased at $19 \mathrm{~h}$ and at 40; 0.4 and $0.63 \mu \mathrm{g} \mathrm{Cu}\left(\mathrm{mg} \mathrm{dw}^{-1}\right.$ respectively. Unexpectedly, a tiny amount of copper was detected on the surface of cells growing at no-added copper, $0.02 \mu \mathrm{g} \mathrm{Cu}(\mathrm{mg} \mathrm{dw})^{-1}$. The residual copper in the spent NMS media was found to gradually increase with time. Likewise with the copper associated with biomass, the residual copper was small (less than $0.05 \mu \mathrm{g} \mathrm{Cu} \mathrm{ml}^{-1}$ ) at the first seven time points tested (0h-17h). At the last two time points (19h and $40 \mathrm{~h})$, the residual copper was found to increase to 0.08 and $0.24 \mu \mathrm{g} \mathrm{Cu}$ $\mathrm{ml}^{-1}$. These results showed that most of copper was taken up by $M$. capsulatus growing on low-copper medium until a certain point at which less copper was needed to sustain metabolic processes inside the cells. Then, any excess copper was retained, associated with biomass.

\section{DISCUSSION}

The work done in this study describes an attempt to investigate some physiological features of M. capsulatus during growth on no-added copper (expressing sMMO) or high copper (expressing pMMO). Two important factors were considered in this study; which copper concentration to use and at which sampling time intervals. Selecting which copper concentration that could be added and time points that could be taken built on the work done by Nielsen et al., [14]. In their study, no sMMO transcripts were detected after 20 minutes of addition of $50 \mu \mathrm{M}$ copper as a final concentration indicating significant suppression of sMMO transcription. Therefore, our approach is to explore what was happening in those 20 minutes in terms of regulation of sMMO, which took place within that period. Because the addition of such a high copper concentration to $M$. capsulatus is likely to induce stress-response genes, some modifications were introduced. Choosing a moderate copper concentration $(30 \mu \mathrm{M})$, adding copper gradually, and taking samples in a narrow range (minutes initially) are probably the most effective way to detect the changes of regulatory proteins during the copper switch from sMMO to pMMO.

The activity of sMMO enzyme was assessed using a colorimetric test [15]. This test is based on the ability of the cell to oxidize naphthalene into naphthol and as pMMO does not have this ability, the test is sMMO-specific. The gradual decrease in the purple colour intensity upon gradual copper addition over indicates that SMMO activity diminished until it became fully inactive after 4 hours of adding copper. However, the switch from sMMO to pMMO seemed to take place between 2 - 4h. These results are consistent with those obtained by Nielsen et al. [14], who reported that sMMO activity was decreased to $50 \%$ after one hour of addition of $50 \mu \mathrm{M}$ copper and was completely inhibited after two hours.

To check the polypeptides profile of sMMO and pMMO, SDS-PAGE of whole-cell extract was carried out. As expected, the three subunits of the sMMO hydroxylase were detected with a gradual decrease in the band intensities from $0-4 \mathrm{~h}$ indicating the expression of polypeptide has ceased and a possible turnover of these polypeptides took place. On the other hand, the $\alpha-, \beta$ - and $\gamma$-subunits of the hydroxylase of pMMO were also identified with increased band intensity with time. These findings are in agreement with what is known about pMMO; pMMO is expressed as a basal level even at no-added copper, however, its abundance and activity increased in response to added copper [10]. The time point at which the shift from sMMO to pMMO -at the level of polypeptides- appeared to happen at about $4 \mathrm{~h}$. These observations are congruent with those obtained from the naphthalene assay.

With the exception of the $\gamma$-subunit (MmoZ) of the sMMO hydroxylase, mass spectrometry analysis of the selected bands of $M$. capsulatus of cell-free extract in the no-added copper or 
added copper growth conditions identified the $\alpha-, \beta-$, and $\gamma$-subunits of the hydroxylase of sMMO or pMMO. It is unclear why the MmoZ was not identified, although the activity of sMMO was high as indicated by results of the naphthalene assay (the deep purple colour (Fig. 2)). However, it is unlikely that MmoZ was degraded during cell-free extract preparation by boiling but this is still a possibility. Many other proteins with unknown functions were also detected. Most abundant proteins in each band are differentially regulated during the copper switch.

Copper distribution of all the samples was measured. In general, the intracellular, extracellular and copper associated with biomass increased by adding copper over the time tested. The detection of copper in the sample at $0 \mathrm{~h}$ where no copper was added is not surprising because copper contamination of the chemical ingredients of NMS medium and water accounts for about $0.8 \mu \mathrm{M}$ copper (data not shown). The cells tend to take up copper more rapidly during the early hours of addition of copper, reflecting their need for this essential element, not only for pMMO expression and activity but also for other copper-requiring enzymes such as cytochrome oxidases. Cells satisfy their need from copper before they restrict the uptake of this metal because it is toxic at high concentrations. The time needed to accomplish this is more likely to be $17 \mathrm{~h}$ after which excess copper is retained on the biomass or in the spent medium. The switch point from sMMO to pMMO seems to take place at $4 \mathrm{~h}$ at which the intracellular copper concentration is $0.37 \mu \mathrm{g} \mathrm{Cu}(\mathrm{mg} \mathrm{dw})^{-1}$. It has been reported that the copper switch point in Ms. trichosporium was above $0.9 \mathrm{nmol}$ of $\mathrm{Cu}$ (mg protein) ${ }^{-1}$ (about $0.11 \mu \mathrm{g} \mathrm{Cu}\left(\mathrm{mg} \mathrm{dw}^{-1}\right.$ ) [16]. This study seems to be the first in addressing the copper switch from sMMO to pMMO in M. capsulatus. Collectively, the data outlined in this work confirm the negative regulation of sMMO and the induction of pMMO by bioavailability of copper.

\section{ACKNOWLEDGMENTS}

Thanks should go to Biological Mass Spectrometry and Proteomics Facility at the University of Warwick, for polypeptides analysis by LC/ECI-MS/MS. This work is supported by grants from the Ministry of Higher Education, Egypt

\section{REFERENCES}

[1] R. S. Hanson and T. E. Hanson. "Methanotrophic bacteria," Microbiol Rev vol. 60, pp.439-471, June 1996.

[2] J. D. Semrau, A. A. DiSpirito, and S. Yoon. "Methanotrophs and copper," FEMS Microbiol Rev vol.34, pp. 496-531, July 2010.

[3] J. C. Murrell, I. R. McDonald, and B. Gilbert, "Regulation of expression of methane monooxygenases by copper ions," Trends Microbiol vol.8, pp.221-225, May 2000.
[4] L. Chistoserdova. "Modularity of methylotrophy, revisited," Environ Microbiol. vol. 13, pp. 2603-2622, October 2011.

[5] T. J .Smith, Y. A Trotsenko, and J. C. Murrell, "Physiology and biochemistry of the aerobic methane oxidizing bacteria," in Handbook of Hydrocarbon and Lipid Microbiology, Edited by K. N. Timmis Vol. 2, Berlin: Springer-Verlag. 2010, pp. 767-780

[6] P. F Dunfield, V. N Khmelenina, N. E.Suzina, Y. A. Trotsenko, and S N. Dedysh, "Methylocella silvestris sp nov., a novel methanotroph isolated from an acidic forest cambisol," Int. J. Syst. Evol. Microbiol. vol. 53, pp. 1231-1239, September 2003.

[7] A. R. Theisen, M. H. Ali, S. Radajewski, M. G. Dumont, P. F. Dunfield, I. R McDonald, S. N. Dedysh, C. B. Miguez, and J. C. Murrell, "Regulation of methane oxidation in the facultative methanotroph," Methylocella silvestris BL2. Mol. Microbiol., vol. 58, pp. 682-692, Novmber 2005.

[8] A. V. Vorobev, M. Baani, N. V. Doronina, A. L.Brady, W. Liesack, P. F. Dunfield, and S. N. Dedysh, "Methyloferula stellata gen. nov., sp. nov., an acidophilic, obligately methanotrophic bacterium possessing only a soluble methane monooxygenase," Int. J. Syst. Evol. Microbiol. vol. 61, pp. 2456-63, October 2010.

[9] S. H. Stanley, S. D. Prior, D. J. Leak, and H. Dalton. "Copper stress underlies the fundamental change in intracellular location of methane monooxygenase in methane oxidizing organisms, studies in batch and continuous cultures," Biotechnol. Lett. vol. 5, pp. 487-492, 1983.

[10] S. D. Prior and H.Dalton. "The effect of copper ions on membrane content and methane monooxygenase activity in methanol-grown cells of Methylococcus capsulatus (Bath)," J. Gen. Microbiol. vol. 131, pp. 155-163, January 1985.

[11] D. W Choi, R.. C. Kunz, E. S Boyd et al., "The membrane associated methane monooxygenase (pMMO) and pMMO-NADH: quinine oxidoreductase complex from Methylococcus capsulatus Bath," $J$ Bacteriol vol. 185, pp. 5755-5764, October 2003.

[12] R . Balasubramanian, S. M .Smith, S. Rawat, L. A. Yatsunyk, T. L. Stemmler, and A. C. Rosenzweig "Oxidation of Methane by a Biological Dicopper Centre," Nature , vol. 465, pp. 115-119, May 2010.

[13] E. C. Fru, "Copper biogeochemistry: A cornerstone in aerobic methanotrophic bacterial ecology and activity?" Geomicrobiol. J. vol. 28, pp. 601-614, 2011

[14] A. K. Nielsen, K. Gerdes, H. Degn, and J. C. Murrell. "Regulation of bacterial methane oxidation, transcription of the soluble methane mono-oxygenase operon of Methylococcus capsulatus (Bath) is repressed by copper ions," Microbiol. vol.142, pp. 1289-1296, May 1996.

[15] G. A Brusseau, H. C., Tsien, R. S. Hanson, and L. P. Wackett. "Optimization of trichloroethylene oxidation by methanotrophs and the use of a colorimetric assay to detect soluble methane monooxygenase activity," Biodegradation vol. 1, pp.19-29, January 1990.

[16] S. Lontoh, and J. D. Semrau. "Methane and trichloroethylene degradation by Methylosinus trichosporium (OB3b) expressing particulate methane monooxygenase," Appl. Environ. Microbiol. vol. 64, pp. 1106-1114, March 1998.

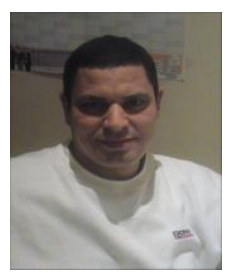

Ashraf Khalifa is a lecturer of Microbiology, Botany Department, and University of Beni-Suef, Egypt. He completed his $\mathrm{PhD}$ in 2012 from the University of Warwick, England studying gene regulation in methanotrophs. 